\title{
Minimally invasive surgery alone compared with intensity-modulated radiotherapy for primary stage I nasopharyngeal carcinoma
}

\author{
You-Ping Liu ${ }^{1,2+}$, Xing Lv ${ }^{1,2+}$, Xiong Zou ${ }^{1,2}$, Yi-Jun Hua ${ }^{1,2}$, Rui You ${ }^{1,2}$, Qi Yang ${ }^{1,2}$, Le Xia ${ }^{1,2}$, Shao-Yan Guo ${ }^{1,2}$, \\ Wen Hu ${ }^{1,2}$, Meng-Xia Zhang ${ }^{1,2}$, Si-Yuan Chen ${ }^{1,2}$, Mei Lin ${ }^{1,2}$, Yu-Long Xie ${ }^{1,2}$, Li-Zhi Liü ${ }^{2,3}$, Rui Sun ${ }^{1,2}$, \\ Pei-Yu Huang ${ }^{1,2}$, Wei Fan ${ }^{2,4}$, Xiang Guo ${ }^{1,2}$, Ming-Huang Hong ${ }^{2,5}$ and Ming-Yuan Chen ${ }^{1,2^{*}}$ (D)
}

\begin{abstract}
Background: The National Comprehensive Cancer Network guidelines recommend intensity-modulated radiotherapy (IMRT) as the primary curative treatment for newly diagnosed nasopharyngeal carcinoma (NPC), but the radiation-related complications and relatively high medical costs remain a consequential burden for the patients. Endoscopic nasopharyngectomy (ENPG) was successfully applied in recurrent NPC with radiation free and relatively low medical costs. In this study, we examined whether ENPG could be an effective treatment for localized stage I NPC.

Methods: Ten newly diagnosed localized stage I NPC patients voluntarily received ENPG alone from June 2007 to September 2017 in Sun Yat-sen University Cancer Center. Simultaneously, the data of 329 stage I NPC patients treated with IMRT were collected and used as a reference cohort. The survival outcomes, quality of life (QOL), and medical costs between two groups were compared.

Results: After a median follow-up of 59.0 months (95\% Cl 53.4-64.6), no death, locoregional recurrence, or distant metastasis was observed in the 10 patients treated with ENPG. The 5-year overall survival, local relapse-free survival, regional relapse-free survival, and distant metastasis-free survival among the ENPG-treated patients was similar to that among the IMRT-treated patients (100\% vs. $99.1 \%, 100 \%$ vs. $97.7 \%, 100 \%$ vs. $99.0 \%, 100 \%$ vs. $97.4 \%$, respectively, $P>0.05$ ). In addition, compared with IMRT, ENPG was associated with decreased total medical costs ( $\$$ $4090.42 \pm 1502.65$ vs. $\$ 12620.88 \pm 4242.65, P<0.001)$ and improved QOL scores including dry mouth $(3.3 \pm 10.5$ vs. $34.4 \pm 25.8, P<0.001)$ and sticky saliva ( $3.3 \pm 10.5$ vs. $32.6 \pm 23.3, P<0.001)$.

Conclusions: ENPG alone was associated with promising long-term survival outcomes, low medical costs, and satisfactory QOL and might therefore be an alternative strategy for treating newly diagnosed localized stage I NPC patients who refused radiotherapy. However, the application of ENPG should be prudent, and prospective clinical trials were needed to further verify the results.
\end{abstract}

Keywords: Nasopharyngeal carcinoma, Localized, Early stage, Endoscopic nasopharyngectomy, Intensity-modulated radiotherapy, Survival, Medical cost, Quality of life

\footnotetext{
*Correspondence: chmingy@mail.sysu.edu.cn

${ }^{\dagger}$ You-Ping Liu and Xing Lv contributed equally to this study

1 Department of Nasopharyngeal Carcinoma, Sun Yat-sen University

Cancer Center, 651 Dongfeng East Road, Guangzhou 510060,

Guangdong, P. R. China

Full list of author information is available at the end of the article
}

(c) The Author(s) 2019. This article is distributed under the terms of the Creative Commons Attribution 4.0 International License (http://creativecommons.org/licenses/by/4.0/), which permits unrestricted use, distribution, and reproduction in any medium, provided you give appropriate credit to the original author(s) and the source, provide a link to the Creative Commons license, and indicate if changes were made. The Creative Commons Public Domain Dedication waiver (http://creativecommons.org/ publicdomain/zero/1.0/) applies to the data made available in this article, unless otherwise stated. 


\section{Background}

Nasopharyngeal carcinoma (NPC) is rare worldwide but common in China, Southeast Asia, and North Africa, with the highest incidence in Southern China [1-3]. Unlike other head and neck cancers, NPC is considered "unresectable" due to high-frequency of extracavity involvement, regional metastasis at diagnosis and the difficulty of the surgical approach to the nasopharynx. Radiotherapy is currently regarded as the only curative option for stage I NPC according to National Comprehensive Cancer Network (NCCN) guidelines. Although mortality rates among patients with stage I NPC treated with intensity-modulated radiotherapy (IMRT) are less than 5\% [4, 5], almost all patients develop mild to moderate acute toxicities, including mucositis, pharyngitis and xerostomia, with subsequent consequences for quality of life (QOL) during convalescence $[5,6]$. In addition, the low cost effectiveness and late complications of IMRT cannot be ignored.

With the popularity of health education and the development of early cancer screening in NPC, an increasing number of NPC patients with early stage cancer were screened and diagnosed. $17.3 \%$ to $47.1 \%$ of patients were found in stage I $[7,8]$, with the lesion limited in the nasopharyngeal cavity in the early screening population, allowing them to be radically and surgically resected. Furthermore, with the development of nasal endoscopic techniques in recent decades, the endoscopic endonasal approach (EEA) allows surgeons to treat many deeply located tumors, even those once considered "inoperable", without functional disability. We developed a novel endoscopic nasopharyngectomy (ENPG) [9-11] and applied this technique in recurrent NPC (rNPC) in 2004 [12-14]. Our previous studies have shown that salvage ENPG resulted in better overall survival (OS) and less posttreatment complications and medical costs than salvage IMRT [13].

These results suggest that it is theoretically possible to radically excise newly diagnosed localized stage I NPC lesions with ENPG and avoid radiation-related toxicities. Here, we report our initial experience with ENPG alone in localized stage I NPC, aiming to assess the efficiency, microinvasion and cost effectiveness of ENPG as an alternative for IMRT in localized stage I NPC.

\section{Methods}

\section{Patient selection}

A total of 490 patients who were newly diagnosed with stage I NPC were identified from an inpatient database at the Sun Yat-sen University Cancer Center (Guangzhou, China) from June 2007 to September 2017.
Our NPC research team, consisting of head and neck surgeons, radiation oncologists, medical oncologists, pathologists, radiologists, and nuclear medicine physicians, established the indication, relative contraindication, and absolute contraindication criteria for applying ENPG in the localized stage I NPC.

The indication criteria for ENPG were: (1) had a maximum diameter of the primary tumor $\leq 1.5 \mathrm{~cm}$; (2) distance of the tumor margin to the internal carotid artery was $\geq 0.5 \mathrm{~cm}$; (3) the minimal axial diameter in magnetic resonance imaging (MRI) was no more than $0.4 \mathrm{~cm}$ for retropharyngeal lymph nodes (RPLN) and $0.6 \mathrm{~cm}$ for cervical lymph node (CLN). Relative contraindications criteria for ENPG were: (1) exogenous tumor diameter $>1.5 \mathrm{~cm}$ but tumor basis $\leq 1.5 \mathrm{~cm}$; (2) RPLN and CLN ranged $0.4-0.5 \mathrm{~cm}$ and $0.6-1.0 \mathrm{~cm}$, respectively, for minimal diameter but was proved negative by ${ }^{18} \mathrm{~F}$-fluorodeoxyglucose positron emission tomography and computed tomography (PET/CT) or pathology. Absolute contraindications criteria for ENPG were: (1) tumor basis diameter $>1.5 \mathrm{~cm}$, or occupied the entire nasopharyngeal cavity; (2) T2-T4 primary tumor, i.e. tumor involving to or beyond the pharyngobasilar fascia; (3) N1-N3 regional lymph node metastasis. i.e. LN with central necrosis or annular enhancement, or groups of two or more lymph nodes (the minimal diameter $\geq 8 \mathrm{~mm}$ for CLN), or minimal diameter $\geq 0.5 \mathrm{~cm}$ for RPLN, or minimal diameter $\geq 1.0 \mathrm{~cm}$ for CLN; (4) had distant metastasis, i.e. bone, liver, or lung metastasis; (5) was physiologically unsuitable for surgery.

In the present study, the inclusion and exclusion criteria for applying ENPG were as follows:

Inclusion criteria: (1) all patients were previously untreated, pathologically diagnosed with undifferentiated or differentiated, keratinizing or nonkeratinizing NPC; (2) staged as T1N0M0 classification; stage I according to the 8th edition staging system of the American Joint Committee on Cancer [AJCC], referring to primary tumors confined in the nasopharyngeal cavity, and the RPLN and CLN were no more than $0.5 \mathrm{~cm}$ and $1.0 \mathrm{~cm}$ respectively. Of note, the inclusion criteria also comprised of patients with relative contraindications. Exclusion criteria: (1) in accordance with the absolute contraindications criteria; (2) without intention to surgery.

All patients provided preoperative written informed consent. The study was approved by the ethical committee of Sun Yat-Sen University Cancer Center.

\section{Treatment procedures}

The detailed procedures for administrating ENPG were performed as previously reported $[9,10]$. All operations were performed under systemic anesthesia with an 
electrotome guided by a 4-mm rigid endoscope $\left(0^{\circ}\right.$ and $30^{\circ}$, Karl-Storz, Tuttlingen, Germany).

Before the operation, our NPC research team first defined the tumor invasion regions and surgical margins for high-risk microinvasion regions, such as gross tumor volume (GTV) and high risk clinical target volume (CTV1) in radiotherapy, respectively [15]. In principle, surgical margins were defined as the tumor invasion regions plus an additional $0.5-1.0 \mathrm{~cm}$ peripheral mucosal margin and a 2-3 $\mathrm{mm}$ basal margin on the surface of the sphenoid bone and the clivus in the skull base (Fig. 2ac). The surgeons were required to strictly follow this planned surgical boundary to remove the tumor during the dissection.

Commonly, the posterior column of the nasal septum was first removed, then the mucoperiosteum in the roof wall of the nasopharynx was separated from the surface of the sphenoid to the clivus. After excising the bilateral eustachian cartilage from the pharyngeal recess under the mucous membrane and foramen lacerum, we separated the posterior nasopharyngeal mucoperiosteum along the clivus. After that, the mucoperiosteum at the level of the soft palate from the surface of the prevertebral muscle was isolated and subsequently turned upward to meet the other resection margins. Thus, the whole nasopharyngeal cavity mucosa including the swelling around the tumor was removed en bloc. To recover the defect, the nasal septum and floor mucosa were separated from the surface of the bone, and only a narrow posterior pedicle above the posterior naris remained to contain the posterior septal artery. The flap was then gently rotated backward and unrolled to cover the nasopharyngeal defect.

Radiotherapy was administered with IMRT techniques. Target volumes definition were as previously reported [15]. The prescribed dose was 66-70 Gy, 60-62 Gy, and 54-56 Gy, in 28-33 fractions, for the planning target volumes (PTVs) derived from GTV, CTV1, and the low-risk clinical target volume (CTV2), respectively. GTV was determined by physical examination, imaging (including MRI and PET/CT, if available) and endoscopic findings. CTV1 was defined as the GTV region plus an additional anterior, superior, inferior and lateral margin of $5 \mathrm{~mm}$ to $1 \mathrm{~cm}$ and an additional posterior margin of $2 \mathrm{~mm}$ to $3 \mathrm{~mm}$ (the range of extension was determined by adjacent structural characteristics), the CTV1 volume also included the entire mucosal stratum and $5 \mathrm{~mm}$ of submucosal stratum of the nasopharynx. The CTV2 was defined as the CTV1 region plus an additional anterior, superior, inferior, and lateral margin of $5 \mathrm{~mm}$ to $10 \mathrm{~mm}$ and an additional posterior margin of $2 \mathrm{~mm}$ to $3 \mathrm{~mm}$, and bilateral upper neck lymph node groups that were at risk of potential microscopic spread of disease [15].
Simultaneously integrated boost, with 5 fractions per week, was adopted.

\section{Operation assessments}

The success of the operation was evaluated by the NPC research team, based on the following three conditions: (1) the intraoperative macroscopic observation showed no tumor-like tissues residue (Fig. 2d, h); (2) had negative margins on pathology; and (3) underwent total resection of the planned resection volume, judged by comparison of preoperative magnetic resonance imaging (MRI) to postoperative, within 1 week after the surgery (Fig. 2a-c, e, f, g).

\section{Quality of life and cost effectiveness}

All patients were asked to complete the European Organization for Research and Treatment of Cancer Quality of Life Questionnaire-Core 30 general (EORTC QLQ-C30, version 3) and head and neck-specific (EORTC QLQH\&N35) questionnaires in the latest follow-up [16]. Medical cost data were provided by the financial department of our cancer center, which included examination expenses, hospital bed cost, nursing care, anesthesia, medicine, radiotherapy, operation, blood transfusion, and other treatments related costs $(\$ 1.00=¥ 6.72$ [11th March 2019]).

\section{Follow-up}

The last follow-up date was on May 17, 2019. During the follow-up, the patients usually underwent endoscopies to assess the wound reconstruction every 2 weeks until the wound was completely re-epithelialized. Subsequent follow-up assessments were performed every 3 months during the first year and every 6 months thereafter until the fifth year. Nasopharyngoscopy, MRI of the head and neck, chest radiography, and abdominal sonography were performed at each assessment. Whenever possible, salvage treatments, including radiotherapy, chemotherapy, and surgery were administered to patients after tumor relapse.

\section{Statistical analysis}

Categorical variables were analyzed using the $x^{2}$ test, Fisher's exact test and continuous variables were analyzed using the Mann-Whitney U test. The events for OS, distant metastasis-free survival (DMFS), local relapse-free survival (LRFS) and regional relapse-free survival (RRFS) were death from any cause, distant metastasis, local and regional relapse, respectively. The duration was calculated from the date of diagnosis for NPC to the date of each event or the last follow-up. Survival results were calculated using the Kaplan-Meier method, and differences were compared by log-rank test. All analyses were 
performed using Statistical Product and Service Solutions (SPSS) software (version 22.0, SPSS Inc., Chicago, USA), and a 2 -tailed $P<0.05$ was considered as statistically significant.

\section{Results}

\section{Patients}

From June 2007 to September 2017, a total of 339 patients were found to be eligible after exclusion of patients who underwent two-dimensional radiotherapy (2DRT) and three-dimensional radiotherapy (3DRT). Patients who refused radiotherapy or preferred surgery were treated with ENPG alone if they fit the inclusion criteria, and the rest were treated with IMRT (Fig. 1). Finally, 10 patients with localized stage I NPC accepted the ENPG treatment voluntarily and 329 patients (309 with intension to radiotherapy and 20 with absolute contraindications for ENPG) underwent IMRT. The mean age of the 10 patients with ENPG and 329 patients with IMRT were 47.0 years (range 29 to 73 years) and 45.0 years (range 19 to 75 years), respectively. Table 1 outlined the demographic and clinical characteristics (Table 1). Due to a controversial lymph node in the level II of left neck, which had a maximum minimal diameter of $0.8 \mathrm{~cm}$ in

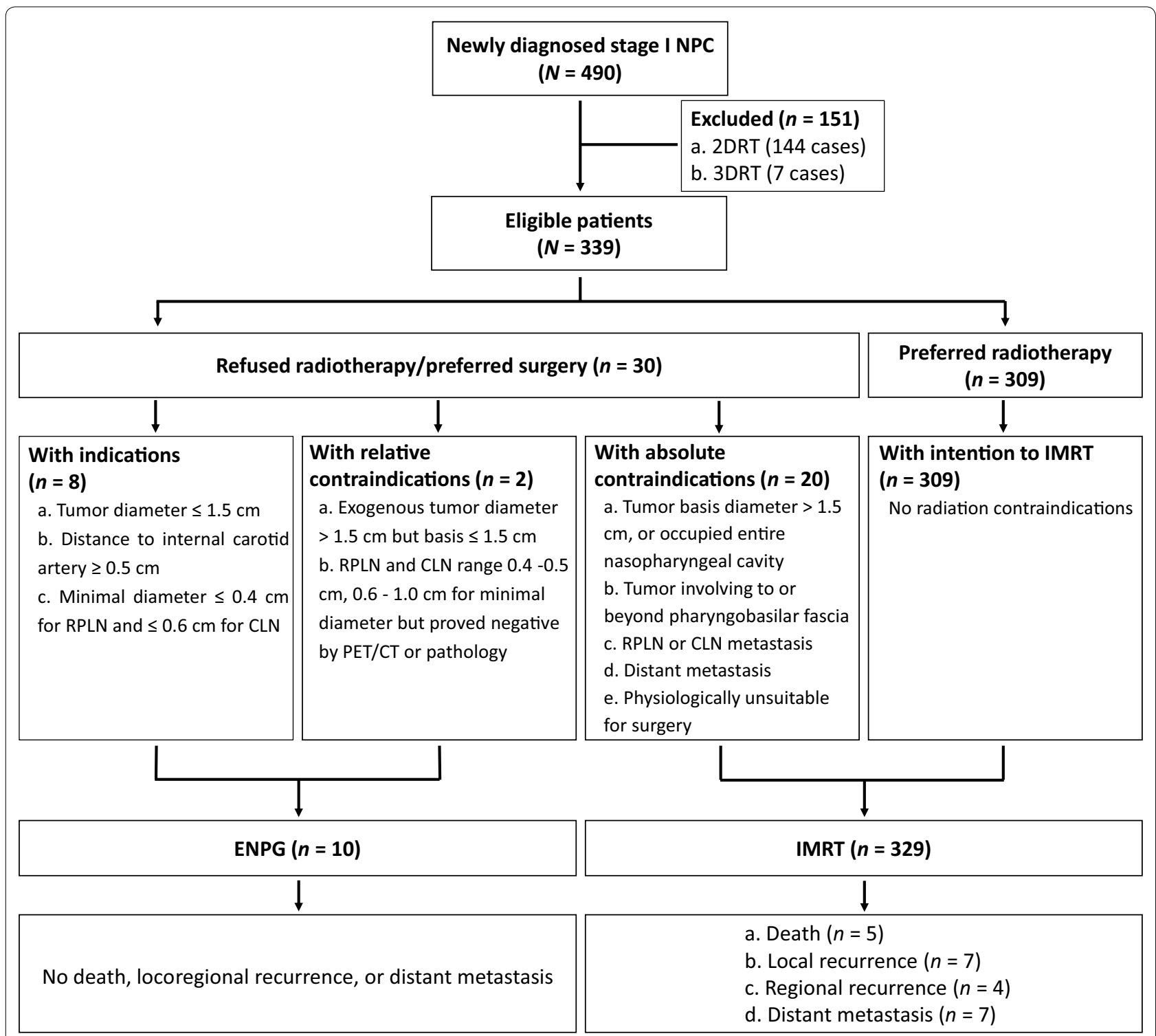

Fig. 1 Work flow diagram. NPC nasopharyngeal carcinoma, 2DRT two-dimensional radiotherapy, 3DRT three-dimensional radiotherapy, RPLN retropharyngeal lymph node, CLN cervical lymph node, PET/CT ${ }^{18}$ F-fluorodeoxyglucose positron emission tomography and computed tomography, ENPG endoscopic nasopharyngectomy, IMRT intensity-modulated radiotherapy 


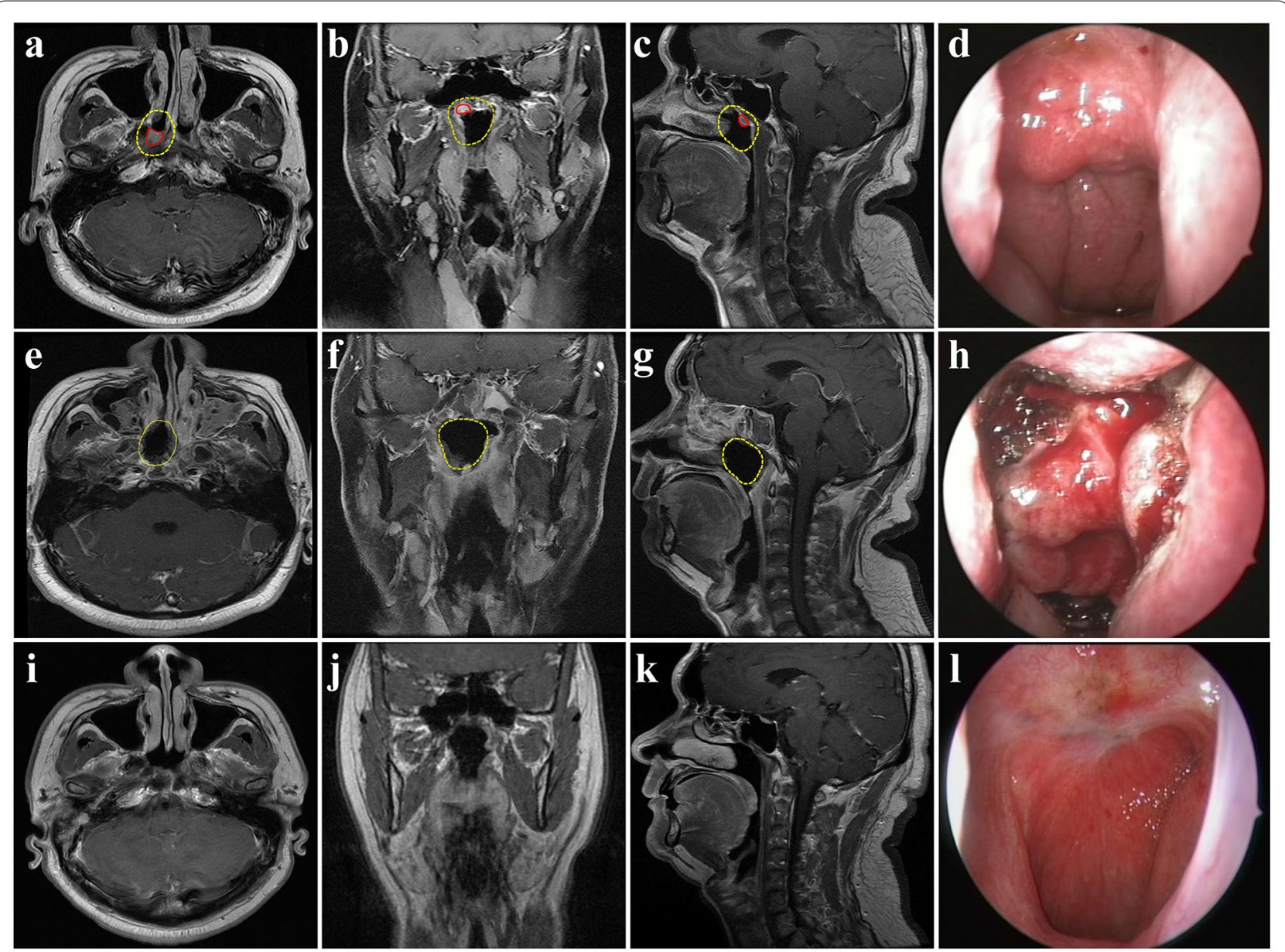

Fig. 2 Magenetic resonance and endoscopic images contrast before and after surgery. a-c shown the tumor invasion regions (red line) and surgical margin (yellow line) in preoperative T1-weighted MR images in horizontal, coronal and sagittal view, respectively. The tumor invasion regions were located in the right superior wall of the nasopharynx and the planed surgical margin which was made by our NPC experts team before surgery covered most of the superior wall and part of the posterior wall of the nasopharynx. $\mathbf{d}$ was the preoperative endoscopic nasopharyngeal image and shown that nodular masses were found in the right superior wall of the nasopharynx, not involving the bilateral pharyngeal recesses and eustachian tubes. e-g shown the resection regions in T1-weighted MR images in horizontal, coronal and sagittal view, respectively, at 3 days after surgery. The surgical defect was highly similar to the planned surgical margin (yellow line). $\mathbf{h}$ shown the endoscopic nasopharynx images during operation, which was marking the resection boundary according to the planed surgical margin delinerated before surgery. i-k shown no abnormal neoplasm was observed in nasopharynx in T1-weighted MR images in horizontal, coronal and sagittal view, respectively, at 10 years after surgery. I shown the synchronous endoscopic nasopharyngeal image and shown the nasopharyngeal defect was re-epithelized and no abnormal neoplasm was observed

MRI but slightly higher ${ }^{18}$ F-FDG uptake in PET/CT, one patient underwent lymphadenectomy before ENPG, and the pathology was confirmed as negative of tumor involvement.

\section{Surgical treatment characteristics}

All operations were safely performed as minimally invasive procedures without any severe surgery-related complications. The median duration of surgery was $92.5 \mathrm{~min}$ (range 60 to $135 \mathrm{~min}$ ). The median quantity of bleeding was $20 \mathrm{~mL}$ (range 10 to $100 \mathrm{~mL}$ ). No patients required blood transfusion. All the multiple margins of biopsies were pathologically negative, and postoperative MRI revealed that all the planned surgical margins of the patients with ENPG were completely resected after comparison to preoperative MRI. Thus, surveillance but not adjuvant radiotherapy or chemotherapy was advised for the 10 ENPG-treated patients. Four patients without nasal flap reconstruction in the operation complained of neck-stiffness-like discomfort or a slight headache. These symptoms disappeared after the surgical defect re-epithelized nearly 1 month after surgery. To alleviate such 
Table 1 Characteristics of stage I patients with ENPG and IMRT

\begin{tabular}{|c|c|c|c|}
\hline Variable & $\begin{array}{l}\text { ENPG } \\
n(\%)\end{array}$ & $\begin{array}{l}\text { IMRT } \\
n(\%)\end{array}$ & $P$ \\
\hline \multicolumn{3}{|l|}{ Gender } & $0.466^{*}$ \\
\hline Female & $3(30.0)$ & $72(21.9)$ & \\
\hline Male & $7(70.0)$ & $257(78.1)$ & \\
\hline $\begin{array}{l}\text { Age [median + SD } \\
\text { (range)] }\end{array}$ & $47.0 \pm 14.5(29-73)$ & $\begin{array}{l}45.0 \pm 10.9 \\
(19-75)\end{array}$ & $0.480^{\#}$ \\
\hline $\begin{array}{l}\text { BMI [mean + SD } \\
\text { (range)] }\end{array}$ & $24.4 \pm 2.7(18.8-27.9)$ & $\begin{array}{l}23.2 \pm 3.0 \\
\quad(15.6-33.4)\end{array}$ & $0.129^{\#}$ \\
\hline \multicolumn{3}{|c|}{ Karnofsky performance status } & $0.215^{*}$ \\
\hline$\geq 90$ & $9(90.0)$ & $322(97.9)$ & \\
\hline$<90$ & $1(10.0)$ & $7(2.1)$ & \\
\hline \multicolumn{3}{|l|}{ Clinical stage } & - \\
\hline I & $10(100.0)$ & $329(100.0)$ & \\
\hline$\|$ & 0 & 0 & \\
\hline III & 0 & 0 & \\
\hline IV & 0 & 0 & \\
\hline \multicolumn{3}{|l|}{ Histology } & $0.306^{*}$ \\
\hline WHOI & 0 & 0 & \\
\hline WHO II & $1(10.0)$ & $11(3.3)$ & \\
\hline WHO III & $9(90.0)$ & $318(96.7)$ & \\
\hline \multicolumn{3}{|l|}{ Smoking history } & $0.461^{*}$ \\
\hline Yes & $1(10.0)$ & $84(25.5)$ & \\
\hline No & $9(90.0)$ & $245(74.5)$ & \\
\hline $\begin{array}{l}\text { Total doses } \\
\text { [mean + SD } \\
\text { (range)] }\end{array}$ & - & $\begin{array}{l}68.85 \pm 1.24 \\
(66.00-70.29)\end{array}$ & - \\
\hline $\begin{array}{l}\text { Fractionated dose } \\
\text { [mean+SD } \\
\text { (range)] }\end{array}$ & - & $\begin{array}{l}2.24 \pm 0.08 \\
\quad(2.00-2.36)\end{array}$ & - \\
\hline \multicolumn{2}{|l|}{ Reconstruction } & - & - \\
\hline Yes & $6(60.0)$ & - & \\
\hline No & $4(40.0)$ & - & \\
\hline
\end{tabular}

ENPG endoscopic nasopharyngectomy, IMRT intensity-modulated radiotherapy, $S D$ standard deviation

* Fisher's exact test

\# Mann-Whitney U test

impacts, the pedicle nasal flap technique was applied for the remaining six patients. The patients did not complain of such discomfort after surgery, and their defects re-epithelized within 2 weeks.

\section{Survival outcomes}

The last follow-up date was May 17, 2019. After a median follow-up of 59.0 months (95\% CI 53.4-64.6), no patients developed tumor recurrence or metastasis, and no death was observed among the 10 patients with ENPG. One of them had a squamous cell carcinoma of the trachea at 5 years after the ENPG surgery. He underwent concurrent chemoradiotherapy for trachea carcinoma. The tumor achieved a complete response and had no progression at last follow-up.

The 5-year OS, LRFS, RRFS and DMFS among the patients with ENPG was 100\% and those with IMRT in the reference cohort were $99.1 \%, 97.7 \%, 99.0 \%$ and $97.4 \%$, respectively, which were similar to those among patients with ENPG $(P>0.05)$ (Fig. 3).

\section{Life quality outcomes and cost effectiveness}

A total of 10 patients who underwent ENPG and 220 patients who underwent IMRT completed the questionnaires. ENPG was found to be slightly better than IMRT in the score assessment regarding items in QLQ-C30 and QLQ-H\&N35, especially in terms of pain $(0 \pm 0 \mathrm{vs.}$ $4.1 \pm 7.4, P=0.042)$, swallowing $(0 \pm 0$ vs. $11.4 \pm 18.5$, $P=0.016)$, dry mouth $(3.3 \pm 10.5$ vs. $34.4 \pm 25.8$, $P<0.001)$ and sticky saliva $(3.3 \pm 10.5$ vs. $32.6 \pm 23.3$, $P<0.001$ ) (Table 2). All 10 patients who underwent ENPG were alive without obvious late complications (Table 3).

The direct cost and total treatment cost for these 10 patients with ENPG were $\$ 1260.60 \pm 636.48$ and $\$ 4090.42 \pm 1502.65$, which were obviously less than those for patients who underwent IMRT (\$9647.39 \pm 2676.09 and $\$ 12,620.88 \pm 4242.65, P<0.001$ ) (Table 4).

\section{Discussion}

We reported that the application of ENPG alone for localized stage I NPC and showed that ENPG achieved satisfactory oncological outcomes for localized stage I NPC, with a 5-year OS, LRFS, RRFS and DMFS all of $100 \%$. Compared with the simultaneous period stage I IMRT-treated patients, ENPG presented with similar survival outcomes, but had better QOL, in terms of dry mouth and sticky saliva, and its total medical cost was cheaper, which indicated that ENPG might be an effective treatment for localized stage I NPC.

Radiotherapy has been recommended as the primary choice of radical treatment for NPC by the NCCN guidelines, and IMRT is the preferred method $[17,18]$. However, oncologists are occasionally faced with patients' refusal to radiotherapy and tendency to surgery. Some patients with satisfactory QOL might worry about radiation-related toxicities [19-22], which could have a relatively high acute severe mucositis rate of $32.5 \%$ [23] and late xerostomia rate of $61.5 \%$ [5], even for early stage NPC treated with radiotherapy alone. Additionally, severe toxicities, such as hyposalivation [20], dysphagia, skin and soft tissue damage caused by neck irradiation [19], could also compromise different aspects of the QOL of patients. In the current study, patients refused radiotherapies for different reasons, such as pregnancy, financial difficulty, 


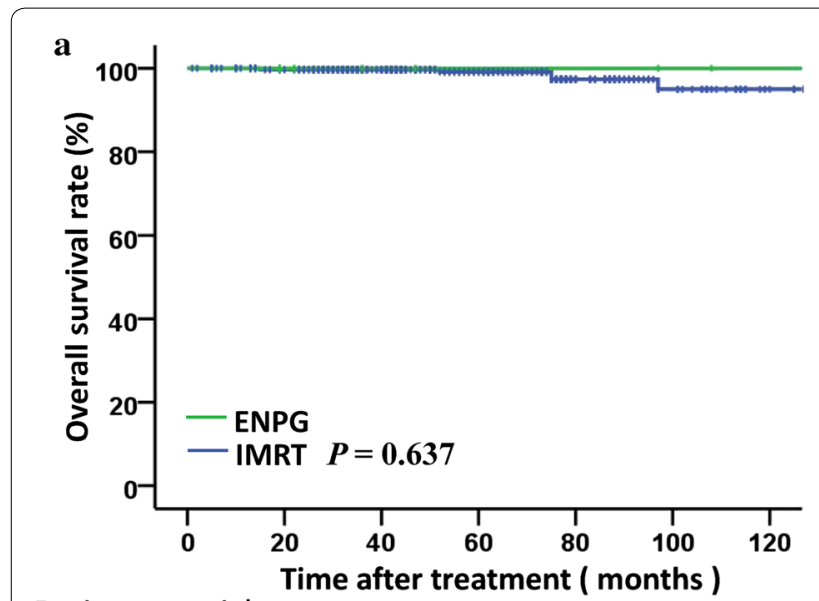

Patients at risk

$\begin{array}{cccccccc}\text { ENPG } & 10 & 7 & 5 & 4 & 4 & 3 & 2 \\ \text { IMRT } & 329 & 309 & 234 & 160 & 83 & 38 & 18\end{array}$

c

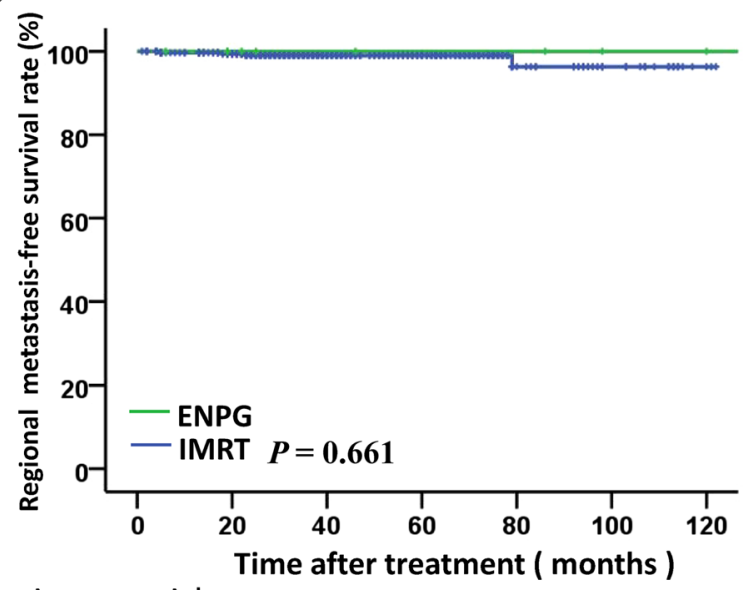

Patients at risk

$\begin{array}{llllllll}\text { ENPG } & 10 & 7 & 5 & 4 & 4 & 2 & 1\end{array}$

$\begin{array}{llllllll}\text { IMRT } & 329 & 280 & 165 & 98 & 32 & 17 & 2\end{array}$

b

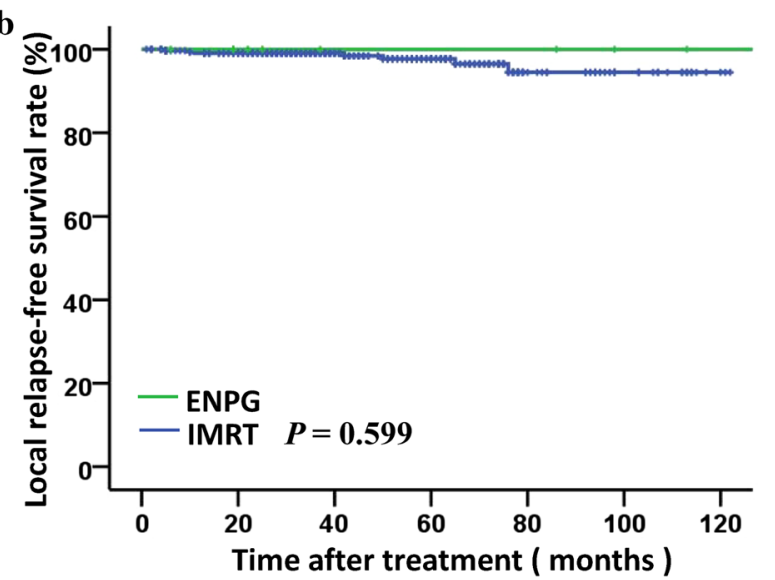

Patients at risk

$\begin{array}{cccccccc}\text { ENPG } & 10 & 7 & 4 & 4 & 4 & 2 & 1 \\ \text { IMRT } & 329 & 278 & 164 & 97 & 32 & 17 & 2\end{array}$

d

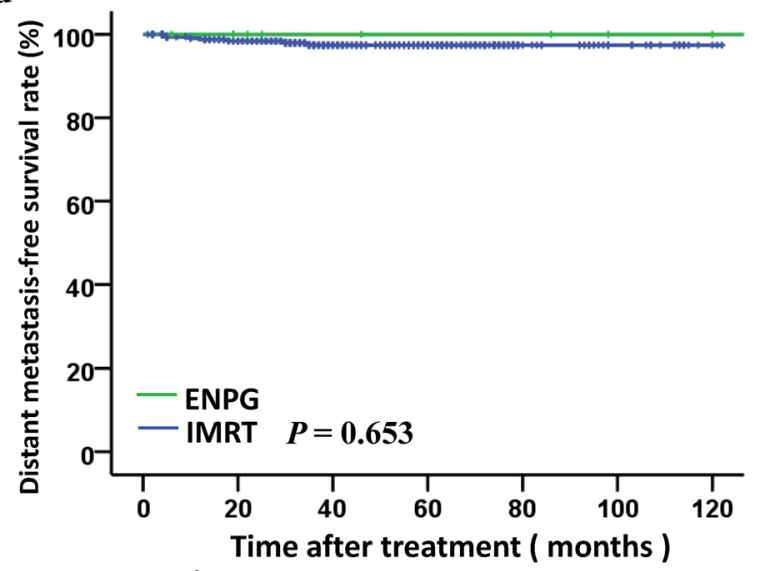

Patients at risk

$\begin{array}{llllllll}\text { ENPG } & 10 & 7 & 5 & 4 & 4 & 2 & 1\end{array}$

Fig. 3 Kaplan-Meier curves of overall survival (a), local relapse-free survival (b), regional relapse-free survival (c) and distant metastasis-free survival (d) for stage I NPC patients with ENPG and IMRT. ENPG endoscopic nasopharyngectomy, IMRT intensity modulated radiation therapy

claustrophobia. For these patients, surgical treatment was the preferred choice. However, only open surgery, such as the maxillary swing approach, transpalatal approach, and transmandibular transpterygoid approach, was used for recurrent NPC in the past [24]. Open surgery was often accompanied with high rates of complications, including soft palate dysfunction (54.8\%), trismus (48.4\%), secretory otitis media (64.5\%), dysphagia (38.7\%), nasal regurgitation (25.8\%), and positive tumor margin (29.0\%) [25], which was repellent for both doctors and patients. Minimal invasive surgery was needed but evidence of its performance in literature was lacking.
With the development of sinus endoscopy, EEA could be performed as a less invasive procedure for the removal of the nasopharyngeal tumor [26], however, there were still several limitations when applying the radical excision of NPC because of the inconvenience of operating through a narrow nasal cavity, difficulties in achieving en bloc excision, and problems in wound healing. To overcome these limitations, a technical system was established and successfully employed for recurrent NPC using endoscopic nasopharyngectomy combined with pedicle nasal septum and floor mucoperiosteal flap reconstruction $[9,10,14]$. Based on the technical system, 
Table 2 Inquiry of quality of life using the QLQ-C30, QLQH\&N35

\begin{tabular}{|c|c|c|c|}
\hline EORTC scale score & $\begin{array}{l}\text { ENPG }(N=10) \\
\text { Mean } \pm \text { SD }\end{array}$ & $\begin{array}{l}\text { IMRT }(N=220) \\
\text { Mean } \pm \text { SD }\end{array}$ & $P$ \\
\hline \multicolumn{4}{|l|}{ QLQ-C30 } \\
\hline Global health status & $99.2 \pm 2.6$ & $96.5 \pm 11.5$ & 0.638 \\
\hline \multicolumn{4}{|l|}{ Functional scales } \\
\hline Physical functioning & $98.7 \pm 2.8$ & $96.6 \pm 14.4$ & 0.738 \\
\hline Role functioning & 100 & $97.4 \pm 14.9$ & 0.568 \\
\hline Emotional functioning & $99.2 \pm 2.6$ & $98.5 \pm 7.0$ & 0.643 \\
\hline Cognitive functioning & $96.7 \pm 7.0$ & $97.7 \pm 8.3$ & 0.336 \\
\hline Social functioning & 100 & $97.4 \pm 14.5$ & 0.540 \\
\hline \multicolumn{4}{|l|}{ Symptom scales } \\
\hline Fatigue & $1.1 \pm 3.5$ & $2.2 \pm 12.0$ & 0.402 \\
\hline Nausea and vomiting & 0 & $0.2 \pm 2.5$ & 0.763 \\
\hline Pain & 0 & $2.3 \pm 10.2$ & 0.449 \\
\hline Dyspnea & 0 & $0.6 \pm 4.5$ & 0.668 \\
\hline Insomnia & 0 & $1.7 \pm 9.1$ & 0.540 \\
\hline Appetite loss & 0 & $8.3 \pm 15.8$ & 0.086 \\
\hline Constipation & 0 & $0.3 \pm 3.2$ & 0.763 \\
\hline Diarrhea & 0 & $0.2 \pm 2.2$ & 0.831 \\
\hline Financial difficulties & 0 & $2.4 \pm 14.4$ & 0.568 \\
\hline \multicolumn{4}{|l|}{ QLQ-H \& N35 } \\
\hline Pain & 0 & $4.1 \pm 7.4$ & 0.042 \\
\hline Swallowing & 0 & $11.4 \pm 18.5$ & 0.016 \\
\hline Senses problems & $3.3 \pm 10.5$ & $2.3 \pm 7.8$ & 0.884 \\
\hline Speech problems & 0 & $1.7 \pm 5.6$ & 0.307 \\
\hline Social eating & $1.7 \pm 3.5$ & $4.3 \pm 9.6$ & 0.431 \\
\hline Social contact & 0 & $1.2 \pm 7.0$ & 0.568 \\
\hline Sexuality & 0 & $2.9 \pm 12.4$ & 0.394 \\
\hline Teeth & $3.3 \pm 10.5$ & $5.5 \pm 15.0$ & 0.749 \\
\hline Opening mouth & 0 & $5.5 \pm 12.4$ & 0.165 \\
\hline Dry mouth & $3.3 \pm 10.5$ & $34.4 \pm 25.8$ & $<0.001$ \\
\hline Sticky saliva & $3.3 \pm 10.5$ & $32.6 \pm 23.3$ & $<0.001$ \\
\hline Coughing & 0 & $0.8 \pm 5.0$ & 0.631 \\
\hline Felt ill & 0 & $3.3 \pm 17.1$ & 0.515 \\
\hline Pain killers & 0 & $2.7 \pm 18.9$ & 0.631 \\
\hline Nutritional supplements & 0 & $3.6 \pm 23.1$ & 0.598 \\
\hline Feeding tube & 0 & $0.5 \pm 6.7$ & 0.831 \\
\hline Weight loss & $10.0 \pm 31.6$ & $10.0 \pm 45.7$ & 0.572 \\
\hline Weight gain & 0 & $2.7 \pm 16.3$ & 0.597 \\
\hline
\end{tabular}

Italic values indicate significance of $P$ value $(P<0.05)$

EORTC the European Organization for Research and Treatment of Cancer, QLQ-C30 Quality-of-Life Questionnaire-Core 30 general, QLQ-H\&N35 head and Neck-specific questionnaires, ENPG endoscopic nasopharyngectomy, IMRT intensity-modulated radiotherapy, SD standard deviation

ENPG broke through the limitations and achieved satisfactory survival outcomes and QOL in locally recurrent NPC [13]. This shows that ENPG could be technically feasible for primary localized stage I NPC.
Table 3 Late treatment-related complications

Complications ENPG $(N=10) \quad$ IMRT $(N=220)$

n $\%$

Auditory/hearing

0.069

$\begin{array}{lllll}0 & 10 & 100 & 138 & 62.7\end{array}$

$\begin{array}{lllll}1-2 & 0 & 0 & 63 & 28.7\end{array}$

$\begin{array}{lllll}3-4 & 0 & 0 & 19 & 8.6\end{array}$

Trismus

8.6

$\begin{array}{lllll}0 & 10 & 100 & 184 & 83.6\end{array}$

$\begin{array}{lllll}1-2 & 0 & 0 & 36 & 16.4\end{array}$

$\begin{array}{lllll}3-4 & 0 & 0 & 0 & 0\end{array}$

Dysphagia

$\begin{array}{lrlrll}0 & 10 & 100 & 190 & 86.4 & \\ 1-2 & 0 & 0 & 26 & 11.8 & \\ 3-4 & 0 & 0 & 4 & 1.8 & \\ \text { Skin } & & & & & 1.000\end{array}$

$\begin{array}{lllll}0 & 9 & 90.0 & 193 & 87.7\end{array}$

$\begin{array}{lllll}1-2 & 1 & 10.0 & 25 & 11.4\end{array}$

$\begin{array}{lllll}3-4 & 0 & 0 & 2 & 0.9\end{array}$

Subcutaneous soft tissue

$\begin{array}{lclrl}0 & 10 & 100 & 193 & 87.7 \\ 1-2 & 0 & 0 & 27 & 12.3 \\ 3-4 & 0 & 0 & 0 & 0\end{array}$

0.611

Dry mouth

$\begin{array}{lllll}0 & 9 & 90.0 & 52 & 23.6\end{array}$

$\begin{array}{lllll}1-2 & 1 & 10.0 & 119 & 54.1\end{array}$

$\begin{array}{lllll}3-4 & 0 & 0 & 49 & 22.3\end{array}$

Cranial neuropathy

0.473

$\begin{array}{lllll}0 & 10 & 100 & 207 & 94.1\end{array}$

$\begin{array}{lllll}1-2 & 0 & 0 & 13 & 5.9\end{array}$

3-4 $0 \begin{array}{llll}1-2 & 0 & 0 & 0\end{array}$

Peripheral neuropathy 1.000

$\begin{array}{lrlrl}0 & 10 & 100 & 218 & 99.1 \\ 1-2 & 0 & 0 & 2 & 0.9 \\ 3-4 & 0 & 0 & 0 & 0\end{array}$

Endocrine dysfunction

$\begin{array}{lrlrl}0 & 10 & 100 & 211 & 95.9 \\ 1-2 & 0 & 0 & 9 & 4.1 \\ 3-4 & 0 & 0 & 0 & 0\end{array}$

Temporal lobe necrosis

$\begin{array}{lrlrl}0 & 10 & 100 & 205 & 93.2 \\ 1-2 & 0 & 0 & 15 & 6.8 \\ 3-4 & 0 & 0 & 0 & 0\end{array}$

ENPG endoscopic nasopharyngectomy, IMRT intensity-modulated radiotherapy

* Fisher's exact test

In fact, many localized tumors can be cured by endoscopic surgery alone [27, 28]. Endoscopic surgery has been applied in therapy for early gastric cancer [29-31], 
Table 4 Medical cost in hospital stay

\begin{tabular}{|c|c|c|c|c|c|}
\hline \multirow[t]{2}{*}{ Variables } & \multicolumn{2}{|l|}{ ENPG $(n=10)$} & \multicolumn{2}{|l|}{ IMRT $(n=329)$} & \multirow[t]{2}{*}{$P$} \\
\hline & Mean \pm SD & Median & Mean \pm SD & Median & \\
\hline Indirect cost (\$) & $2829.82 \pm 1268.38$ & 3146.43 & $2973.49 \pm 3267.11$ & 2079.57 & 0.890 \\
\hline Hospital bed and nurse cost & $193.79 \pm 133.44$ & 153.29 & $226.86 \pm 251.18$ & 94.12 & 0.472 \\
\hline Total workup & $1126.13 \pm 785.92$ & 934.75 & $1160.24 \pm 742.21$ & 1039.26 & 0.886 \\
\hline Medicine & $1293.68 \pm 641.15$ & 1183.52 & $1350.54 \pm 2734.17$ & 507.27 & 0.948 \\
\hline Others & $216.23 \pm 154.83$ & 219.24 & $235.85 \pm 1186.06$ & 83.53 & 0.958 \\
\hline Direct cost (\$) & $1260.60 \pm 636.48$ & 1176.97 & $9647.39 \pm 2676.09$ & 9482.77 & $<0.001$ \\
\hline Costs of surgery/anesthesia & $1260.60 \pm 636.48$ & 1176.97 & $12.68 \pm 25.21$ & 2.23 & $<0.001$ \\
\hline Radiation session IMRT & 0 & 0 & $9634.71 \pm 2673.39$ & 9459.82 & $<0.001$ \\
\hline Total treatment cost $(\$)$ & $4090.42 \pm 1502.65$ & 4364.48 & $12,620.88 \pm 4242.65$ & $11,693.87$ & $<0.001$ \\
\hline
\end{tabular}

$\$ 1.00=¥ 6.72$ (March 11, 2019)

\$US dollar, ¥ Chinese yuan, ENPG endoscopic nasopharyngectomy, IMRT intensity-modulated radiotherapy, SD standard deviation

colorectal neoplasia [32], glottic cancer [33] and achieved satisfactory outcomes. Among the success factors of surgery, patient selection is of great importance. The NCCN guidelines recommend esophageal, esophagogastric junction and gastric cancers within $2 \mathrm{~cm}$ in diameter and without invading deeper than the superficial submucosa, absence of lymphovascular invasion and clear tumor margins to apply endoscopic resection as a therapeutic method. In this study, a well-cooperated NPC research team was established to perform the selection and exclusion criteria and to address potential adverse events. The distance from the tumor margin to the internal carotid artery was defined as no less than $0.5 \mathrm{~cm}$ to decrease the risk of hemorrhage. Additionally, smaller size $(\leq 1.5 \mathrm{~cm}$ in maximum diameter) was considered more suitable not only for the conveniences of the operation but also for less risk of regional or distant metastasis [34-37]. Considering the high rate of nodal metastasis in NPC, even with T1N0M0 patient which might had potentially nodal metastasis, we required the RPLN and CLN should be no more than $0.4 \mathrm{~cm}$ and $0.6 \mathrm{~cm}$ respectively for minimal axial diameter in MRI, and should be without central necrosis or groups of two or more lymph nodes. As a minimal axial diameter of $0.4 \mathrm{~cm}$ or larger was highly sensitive to the diagnosis of lateral retropharyngeal lymph nodes metastases, with a sensitivity and negative predictive value of $94.6 \%$ and $88.98 \%$ [38], and previous study revealed that $96.5 \%$ CLNs with a minimal axial diameter no more than $0.6 \mathrm{~cm}$ were regarded as negative according to PET/CT diagnosis [39]. If the RPLN and CLN were between $0.4 \mathrm{~cm}$ to $0.5 \mathrm{~cm}, 0.6 \mathrm{~cm}$ to $1.0 \mathrm{~cm}$ for minimal axial diameter respectively, or there was a controversary about the diagnosis of LN metastasis, PET/ $\mathrm{CT}$, core biopsy or excision biopsy and multidisciplinary consultation were to be conducted for confirmation. ENPG was performed after the CLN was proved to be negative.

As to the resection distance from the tumor margin, it was usually based on pathological evidence in other cancers, such as early invasive colorectal carcinoma [40], while it was rare in the past for NPC due to difficulties in acquiring general en bloc tumor specimens. In this study, we refer to the margin of CTV1 in the radiotherapy target, which was defined as GTV plus an additional anterior, superior, inferior, and lateral margin of $5 \mathrm{~mm}$ to $1 \mathrm{~cm}$ and an additional posterior margin of $2 \mathrm{~mm}$ to $3 \mathrm{~mm}$. Further analysis of ENPG specimens might offer further guidance. The absence of local recurrence in these 10 patients indicates that the $0.5-1.0 \mathrm{~cm}$ margin may be enough for localized stage I NPC. Interestingly, we found that in the past, low-risk clinical tumor volume (CTV2) [15], which was defined as CTV1 plus a 0.5$1.0 \mathrm{~cm}$ margin, was commonly set in stage I NPC and required prophylactic irradiation of the bilateral upper neck. However, this CTV2 region and prophylactic irradiation of the bilateral upper neck were absent in all 10 patients who underwent ENPG alone in this study, but none of the patients experienced local relapse, regional relapse or distant metastasis. This phenomenon might bring some new insights to the principles of the radiotherapy target volume outline.

However, considering the novelty in applying radical ENPG for NPC, the high selection criteria of localized stage I cases and very limited number of patients included in this analysis, the clinical application of this procedure should be very prudent. Surveillance for recurrence or metastasis after treatment should be followed precisely, and cooperation in a multidiscipline team should be 
sought before clinical implementation. We have initiated a prospective clinical trial to further evaluate the safety and efficacy of ENPG (ClinicalTrials.gov number, NCT03353467) for localized early stage NPC.

\section{Conclusion}

ENPG alone was associated with promising long-term survival outcomes, low medical costs, and excellent QOL for early stage NPC in our study, which may be an alternative strategy for newly diagnosed patients with localized stage I NPC who refuse IMRT.

\begin{abstract}
Abbreviations
AJCC: American Joint Committee on Cancer; CTV: clinical tumor volume; DMFS: distant metastasis-free survival; EEA: endoscopic endonasal approach; ENPG: endoscopic nasopharyngectomy; EORTC QLQ-H\&N35: European Organization for Research and Treatment of Cancer Quality of Life Questionnaire head and neck-specific; EORTC QLQ-C30: European Organization for Research and Treatment of Cancer Quality of Life Questionnaire-Core 30 general; GTV: gross tumor volume; ICRU: International Commission on Radiation Units and Measurements; IMRT: intensity-modulated radiotherapy; LRFS: local relapse-free survival; MRI: magnetic resonance imaging; NCCN: National Comprehensive Cancer Network; NPC: nasopharyngeal carcinoma; OS: overall survival; PET/CT: ${ }^{18} \mathrm{~F}$-fluorodeoxyglucose positron emission tomography and computed tomography; QOL: quality of life; rNPC: recurrent NPC; RRFS: regional relapse-free survival; WHO: World Health Organization.
\end{abstract}

\section{Acknowledgements}

We thank Miss Wei-Lan Zhuang, Finance Division of Sun Yat-sen University Cancer Center, for her help in acquisition and analysis of the medical cost data of this manuscript.

\section{Authors' contributions}

Study concepts and design: MYC, MHH. Data acquisition: YPL, XL, XZ, YJH. Quality control of data and algorithms: RY, QY. Data analysis and interpretation: YPL, XL, MYC. Manuscript drafting and revision: YPL, XL, XZ, YJH, RY, QY, LX, SYG, WH, MXZ, SYC, ML, YLX, LZL, RS, PYH, WF, XG, MHH, MYC. All authors read and approved the final manuscript.
\end{abstract}

\section{Funding}

Funding was provided by the National Natural Science Foundation of China (Nos. 81572912, 81772895), Guangdong Public Welfare Research and Capacity Building Projects (2014B020212005), the Program of Sun Yat-Sen University for Clinical Research 5010 Program (No. 201310), the Major Project of Sun Yat-Sen University for the New Cross Subject, the Special Support Program for Highlevel Talents in Sun Yat-Sen University Cancer Center (to M.Y. Chen), Guangdong Province Science and Technology Development Special Funds (Frontier and Key Technology Innovation Direction-Major Science and Technology Project), Guangzhou Science and Technology Planning Project—Production and Research Collaborative Innovation Major Project.

\section{Availability of data and materials}

The key raw data have been deposited into the Research Data Deposit (http:// www.researchdata.org.cn), with the Approval Number of RDDA2019001140 and the datasets used in this study are publicly available.

\section{Ethics approval and consent to participate}

For the use of the clinical data for research purposes, prior written informed consents from all patients and approval from the Institute Research Ethics Committee of Sun Yat-sen University Cancer Center were obtained.

\section{Consent for publication}

All the authors have reviewed and approved the final manuscript for publication.

\section{Competing interests}

The authors declare that they have no competing interests.

\section{Author details}

1 Department of Nasopharyngeal Carcinoma, Sun Yat-sen University Cancer Center, 651 Dongfeng East Road, Guangzhou 510060, Guangdong, P. R. China. ${ }^{2}$ State Key Laboratory of Oncology in South China, Collaborative Innovation Center for Cancer Medicine, Guangdong Key Laboratory of Nasopharyngeal Carcinoma Diagnosis and Therapy, Sun Yat-sen University Cancer Center, Guangzhou 510060, Guangdong, P. R. China. ${ }^{3}$ Department of Medical Imaging and Interventional Radiology, Sun Yat-sen University Cancer Center, Guangzhou 510060, Guangdong, P. R. China. ${ }^{4}$ Department of Nuclear Medicine, Sun Yat-sen University Cancer Center, Guangzhou 510060, Guangdong, P. R. China. ${ }^{5}$ Department of Clinical Trials Center, Sun Yat-sen University Cancer Center, Guangzhou 510060, Guangdong, P. R. China.

Received: 13 June 2019 Accepted: 23 October 2019

Published online: 15 November 2019

\section{References}

1. Yu MC, Yuan JM. Epidemiology of nasopharyngeal carcinoma. Semin Cancer Biol. 2002;12(6):421-9.

2. Wei KR, Zheng RS, Zhang SW, Liang ZH, Li ZM, Chen WQ. Nasopharyngeal carcinoma incidence and mortality in China, 2013. Chin J Cancer. 2017;36(1):90. https://doi.org/10.1186/s40880-017-0257-9.

3. Feng RM, Zong YN, Cao SM, Xu RH. Current cancer situation in China: good or bad news from the 2018 Global Cancer Statistics? Cancer Commun (Lond). 2019;39(1):22. https://doi.org/10.1186/s40880-019-0368-6.

4. Zhang MX, Li J, Shen GP, Zou X, Xu JJ, Jiang R, et al. Intensity-modulated radiotherapy prolongs the survival of patients with nasopharyngeal carcinoma compared with conventional two-dimensional radiotherapy: a 10-year experience with a large cohort and long follow-up. Eur J Cancer. 2015;51(17):2587-95. https://doi.org/10.1016/j.ejca.2015.08.006.

5. Su SF, Han F, Zhao C, Chen CY, Xiao WW, Li JX, et al. Long-term outcomes of early-stage nasopharyngeal carcinoma patients treated with intensity-modulated radiotherapy alone. Int J Radiat Oncol Biol Phys. 2012;82(1):327-33. https://doi.org/10.1016/j.jijrobp.2010.09.011.

6. Yi JL, Gao L, Huang XD, Li SY, Luo JW, Cai WM, et al. Nasopharyngeal carcinoma treated by radical radiotherapy alone: ten-year experience of a single institution. Int J Radiat Oncol Biol Phys. 2006;65(1):161-8. https://doi. org/10.1016/j.jijobp.2005.12.003.

7. Chan KCA, Woo JKS, King A, Zee BCY, Lam WKJ, Chan SL, et al. Analysis of plasma Epstein-Barr virus DNA to screen for nasopharyngeal cancer. N Engl J Med. 2017;377(6):513-22. https://doi.org/10.1056/NEJMoa1701717.

8. Ji MF, Huang QH, Yu X, Liu Z, Li X, Zhang LF, et al. Evaluation of plasma Epstein-Barr virus DNA load to distinguish nasopharyngeal carcinoma patients from healthy high-risk populations in Southern China. Cancer. 2014;120(9):1353-60. https://doi.org/10.1002/cncr.28564.

9. Chen MY, Wen WP, Guo X, Yang AK, Qian CN, Hua YJ, et al. Endoscopic nasopharyngectomy for locally recurrent nasopharyngeal carcinoma. Laryngoscope. 2009;119(3):516-22. https://doi.org/10.1002/lary.20133.

10. Chen MY, Wang SL, Zhu YL, Shen GP, Qiu F, Luo DH, et al. Use of a posterior pedicle nasal septum and floor mucoperiosteum flap to resurface the nasopharynx after endoscopic nasopharyngectomy for recurrent nasopharyngeal carcinoma. Head Neck. 2012;34(10):1383-8. https://doi.org/10.1002/ hed.21928.

11. Zou X, Wang SL, Liu YP, Liu YL, Zou RH, Zhang YN, et al. A curative-intent endoscopic surgery for postradiation nasopharyngeal necrosis in patients with nasopharyngeal carcinoma. Cancer Commun (Lond). 2018;38(1):74. https://doi.org/10.1186/s40880-018-0338-4.

12. Zou X, Han F, Ma WJ, Deng MQ, Jiang R, Guo L, et al. Salvage endoscopic nasopharyngectomy and intensity-modulated radiotherapy versus conventional radiotherapy in treating locally recurrent nasopharyngeal carcinoma. Head Neck. 2015;37(8):1108-15. https://doi.org/10.1002/hed.23719.

13. You R, Zou X, Hua YJ, Han F, Li L, Zhao C, et al. Salvage endoscopic nasopharyngectomy is superior to intensity-modulated radiation therapy for local recurrence of selected T1-T3 nasopharyngeal carcinoma - a case-matched comparison. Radiother Oncol J Eur Soc Ther Radiol Oncol. 2015;115(3):399_ 406. https://doi.org/10.1016/j.radonc.2015.04.024. 
14. Chen MY, Guo X, Wen WP, Hua YJ, Guo L, Li NW, et al. Salvage surgical operation via endoscopic transnasal approach for local persistent or recurrent nasopharyngeal carcinoma. Ai zheng $=$ Aizheng $=$ Chin J Cancer. 2007;26(7):673-8.

15. Tang LQ, Chen DP, Guo L, Mo HY, Huang Y, Guo SS, et al. Concurrent chemoradiotherapy with nedaplatin versus cisplatin in stage II-IVB nasopharyngeal carcinoma: an open-label, non-inferiority, randomised phase 3 trial. Lancet Oncol. 2018;19(4):461-73. https://doi.org/10.1016/S1470-2045(18)30104-9.

16. Bjordal K, de Graeff A, Fayers PM, Hammerlid E, van Pottelsberghe C, Curran D, et al. A 12 country field study of the EORTC QLQ-C30 (version 30) and the head and neck cancer specific module (EORTC QLQ-H\&N35) in head and neck patients. EORTC Quality of Life Group. Eur J Cancer. 2000;36(14):1796-807.

17. Chua MLK, Wee JTS, Hui EP, Chan ATC. Nasopharyngeal carcinoma. Lancet. 2016;387(10022):1012-24. https://doi.org/10.1016/S0140-6736(15)00055-0.

18. Lee AW, Ma BB, Ng WT, Chan AT. Management of nasopharyngeal carcinoma: current practice and future perspective. J Clin Oncol. 2015;33(29):3356-64. https://doi.org/10.1200/JCO.2015.60.9347.

19. Pow EH, Kwong DL, Sham JS, Lee VH, Ng SC. Can intensity-modulated radiotherapy preserve oral health-related quality of life of nasopharyngeal carcinoma patients? Int J Radiat Oncol Biol Phys. 2012;83(2):e213-21. https ://doi.org/10.1016/j.ijrobp.2011.12.040.

20. Pow EH, Kwong DL, McMillan AS, Wong MC, Sham JS, Leung LH, et al. Xerostomia and quality of life after intensity-modulated radiotherapy vs. conventional radiotherapy for early-stage nasopharyngeal carcinoma: initial report on a randomized controlled clinical trial. Int J Radiat Oncol Biol Phys. 2006;66(4):981-91. https://doi.org/10.1016/j.jjrobp.2006.06.013.

21. McMillan AS, Pow EH, Kwong DL, Wong MC, Sham JS, Leung LH, et al. Preservation of quality of life after intensity-modulated radiotherapy for early-stage nasopharyngeal carcinoma: results of a prospective longitudinal study. Head Neck. 2006;28(8):712-22. https://doi.org/10.1002/hed.20378.

22. Kwong DL, Pow EH, Sham JS, McMillan AS, Leung LH, Leung WK, et al. Intensity-modulated radiotherapy for early-stage nasopharyngeal carcinoma: a prospective study on disease control and preservation of salivary function. Cancer. 2004;101(7):1584-93. https://doi.org/10.1002/cncr.20552.

23. Chen QY, Wen YF, Guo L, Liu H, Huang PY, Mo HY, et al. Concurrent chemoradiotherapy vs radiotherapy alone in stage II nasopharyngeal carcinoma: phase III randomized trial. J Natl Cancer Inst. 2011;103(23):1761-70. https:// doi.org/10.1093/jnci/djr432.

24. Wei WI, Sham JS. Nasopharyngeal carcinoma. Lancet. 2005;365(9476):204154. https://doi.org/10.1016/S0140-6736(05)66698-6.

25. King WW, Ku PK, Mok CO, Teo PM. Nasopharyngectomy in the treatment of recurrent nasopharyngeal carcinoma: a twelve-year experience. Head Neck. 2000;22(3):215-22.

26. Na'ara S, Amit M, Billan S, Cohen JT, Gil Z. Outcome of patients undergoing salvage surgery for recurrent nasopharyngeal carcinoma: a meta-analysis. Ann Surg Oncol. 2014;21(9):3056-62. https://doi.org/10.1245/s1043 4-014-3683-9.

27. Siegel RL, Miller KD, Jemal A. Cancer Statistics, 2017. CA Cancer J Clin. 2017;67(1):7-30. https://doi.org/10.3322/caac.21387.

28. Cohen JD, Li L, Wang Y, Thoburn C, Afsari B, Danilova L, et al. Detection and localization of surgically resectable cancers with a multi-analyte blood test. Science. 2018;359(6378):926-30. https://doi.org/10.1126/science.aar3247.
29. Okada K, Fujisaki J, Yoshida T, Ishikawa H, Suganuma T, Kasuga A, et al. Long-term outcomes of endoscopic submucosal dissection for undifferentiated-type early gastric cancer. Endoscopy. 2012;44(2):122-7. https://doi. org/10.1055/s-0031-1291486.

30. Lee S, Choi KD, Han M, Na HK, Ahn JY, Jung KW, et al. Long-term outcomes of endoscopic submucosal dissection versus surgery in early gastric cancer meeting expanded indication including undifferentiated-type tumors: a criteria-based analysis. Gastric Cancer. 2018;21(3):490-9. https://doi. org/10.1007/s10120-017-0772-z.

31. Ono H, Kondo H, Gotoda T, Shirao K, Yamaguchi H, Saito D, et al. Endoscopic mucosal resection for treatment of early gastric cancer. Gut. 2001;48(2):225-9.

32. Oka S, Tanaka S, Saito Y, lishi H, Kudo SE, Ikematsu H, et al. Local recurrence after endoscopic resection for large colorectal neoplasia: a multicenter prospective study in Japan. Am J Gastroenterol. 2015;110(5):697-707. https ://doi.org/10.1038/ajg.2015.96.

33. Ansarin M, Zabrodsky M, Bianchi L, Renne G, Tosoni A, Calabrese L, et al. Endoscopic $\mathrm{CO} 2$ laser surgery for early glottic cancer in patients who are candidates for radiotherapy: results of a prospective nonrandomized study. Head Neck. 2006;28(2):121-5. https://doi.org/10.1002/hed.20301.

34. Xiao W, Liu S, Tian Y, Guan Y, Huang S, Lin C, et al. Prognostic significance of tumor volume in locally recurrent nasopharyngeal carcinoma treated with salvage intensity-modulated radiotherapy. PLoS ONE. 2015;10(4):e0125351. https://doi.org/10.1371/journal.pone.0125351.

35. He YX, Wang Y, Cao PF, Shen L, Zhao YJ, Zhang ZJ, et al. Prognostic value and predictive threshold of tumor volume for patients with locally advanced nasopharyngeal carcinoma receiving intensity-modulated radiotherapy. Chin J Cancer. 2016;35(1):96. https://doi.org/10.1186/s40880-016-0159-2.

36. Lin $H$, Lin HX, Ge N, Wang HZ, Sun R, HuWH. Plasma uric acid and tumor volume are highly predictive of outcome in nasopharyngeal carcinoma patients receiving intensity modulated radiotherapy. Radiat Oncol. 2013;8:121. https://doi.org/10.1186/1748-717X-8-121.

37. Guo R, Sun Y, Yu XL, Yin WJ, Li WF, Chen YY, et al. Is primary tumor volume still a prognostic factor in intensity modulated radiation therapy for nasopharyngeal carcinoma? Radiother Oncol. 2012;104(3):294-9. https://doi. org/10.1016/j.radonc.2012.09.001.

38. Zhang GY, Liu LZ, Wei WH, Deng YM, Li YZ, Liu XW. Radiologic criteria of retropharyngeal lymph node metastasis in nasopharyngeal carcinoma treated with radiation therapy. Radiology. 2010;255(2):605-12. https://doi. org/10.1148/radiol.10090289.

39. Peng H, Chen L, Tang LL, Li WF, Mao YP, Guo R, et al. Significant value of (18)F-FDG-PET/CT in diagnosing small cervical lymph node metastases in patients with nasopharyngeal carcinoma treated with intensity-modulated radiotherapy. Chin J Cancer. 2017;36(1):95. https://doi.org/10.1186/s4088 0-017-0265-9.

40. Ueno H, Mochizuki H, Hashiguchi Y, Shimazaki H, Aida S, Hase K, et al. Risk factors for an adverse outcome in early invasive colorectal carcinoma. Gastroenterology. 2004;127(2):385-94.

Ready to submit your research? Choose BMC and benefit from:

- fast, convenient online submission

- thorough peer review by experienced researchers in your field

- rapid publication on acceptance

- support for research data, including large and complex data types

- gold Open Access which fosters wider collaboration and increased citations

- maximum visibility for your research: over 100M website views per year

At $\mathrm{BMC}$, research is always in progress.

Learn more biomedcentral.com/submissions 